\title{
Effects of the Retraining in Endurance on Anthropometric and Metabolic Profiles' Evolution of the Tunisian Obese Pubescent Boys
}

\author{
Sabri Gaied Chortane ${ }^{1}$, Lazhar Zorgui ${ }^{2}$, Maamer Slimani ${ }^{3}$, \\ Rachid Sakly ${ }^{4}$, Zouheir Tabka ${ }^{5}$ and Foued Chéour ${ }^{2}$ \\ ${ }^{1}$ High Institute of Sport and Physical Education of Sfax, Tunisia \\ ${ }^{2}$ High Institute of Applied Biology of Médenine, Tunisia \\ ${ }^{3}$ Faculty of Sciences of Bizerte, Tunisia \\ ${ }^{4}$ Higher School of Health Sciences and Techniques of Monastir, Tunisia \\ ${ }^{5}$ Faculty of Medicine of Sousse, Tunisia
}

\begin{abstract}
Fifty-three Tunisian obese pubescent boys $(15.4 \pm 1.7$ years, $96.4 \pm 13.2 \mathrm{~kg}, 1.71 \pm 0.1 \mathrm{~cm})$ were submitted to a retraining program in endurance for two months which includes three sessions of 45 minutes per week of pedalling on an ergometer cycle and this to assess the effects on anthropometric and metabolic profiles. Our results showed that the retraining in endurance beneficially affects the above parameters such as reflected by the reduction of BMI, and abdominal and hip perimeters decrease. These changes were also accompanied, firstly by the reduction of the levels of glucoses, total cholesterol, LDLc and triglycerides, and secondly by the increase of HDLc amount which has reduced the LDLC/HDLc ratio. A reduction in levels of pro-inflammatory cytokines namely the IL-6 and TNF- $\alpha$ was also observed. We conclude that the retraining in endurance reduces the weight load of the Tunisian obese pubescent boys and improves their metabolic profiles.
\end{abstract}

Keywords: Childhood Obesity; pubescent boys; retraining in endurance; anthropometric and metabolic profiles

\section{Introduction}

Obesity is considered more and more a global problem and affects both young people and older. It is characterized by overweight resulting from a surplus of energy consumption and lack of physical exercises (Must et al., 1999). This anomaly often promotes a large number of diseases which are mainly metabolic, cardiovascular, endocrinologist and inflammatory orders even psychological, and worsening especially as the body mass index (BMI) becomes more important (Rossner and Hallberg, 1978; Cornier et al., 2008) .

Physical activity mainly in endurance plays an important role in weight control and thus promoting energy expenditure (Foshini et al., 2007; Griera et al., 2007). Indeed, the sensitivity of adipose tissue to lipolytic action increases thereby favoring the release of fatty acids and therefore their oxidation mainly in oxidative muscles. However, in children and pubescent, ages often characterized by the development of glycolytic muscles; thereby reducing aerobic capacity and therefore complicates the lipid oxidation and loss of weight (Zunquin et al., 2006). Also, Ross et al. (2000), Dumortier et al. (2003) and Giannopoulou et al. (2005) reported that weight loss or abdominal fat caused by regular exercise and/or diet would improve the glucose intolerance as the insulin resistance in type 2 diabetics and obese people.

The objective of this study was to assess the effects of the retraining in endurance for eight weeks on anthropometric and metabolic profiles' evolution of the Tunisian obese pubescent boys.

\section{Participants}

\section{Materials and methods}

This study was approved in advance by the Regional Ethics Committee was carried out on a carefully selected population of 53 Tunisian obese pubescent boys $(15.4 \pm 1.7$ years, $96.4 \pm 13.2 \mathrm{~kg}, 1.71 \pm 0.1 \mathrm{~cm})$ and this to assess the effects of the retraining in endurance on an ergometer cycle on anthropometric and metabolic profiles. The inclusion criteria were a sedentary lifestyle, excess weight, age ranging from 12 to 18 years and a commitment to follow the program of physical activity in a weight room. The exclusion criteria were the absence of cardiovascular, hepatic, renal, endocrine or psychiatric pathologies, no taking medication affecting body weight, no restrictive regime during the previous year, a sufficient motivation to pass a test maximum effort $\left(\mathrm{VO}_{2} \mathrm{max}\right)$ and no physical handicaps. The participation to the study was voluntary, anonymous and confidential. Throughout the period of submission to retraining program in endurance, athletes followed a life strict hygiene similar favourable to the decrease in weight and the preservation of lean body mass (Brandou $e t$ al., 2003). 


\section{Physical tests and retraining in endurance}

The selected subjects for the study were submitted to a retraining program in endurance during two months which includes three sessions of 45 minutes per week of pedalling on an ergometer cycle with intermittent relaxations of five minutes once the maximum heart rate for each individual is reached and is maintained for ten minutes. The maximum lipid oxidation level (LipoxMax) to the exercise was evaluated by the cardio-respiratory test (Brown et al., 2007). It consists in determining on bicycle ergometer the appropriate levels of heart rate (FCLM) and $\mathrm{VO}_{2}$ which the lipid oxidation of each subject is up following the increase in workload in increments of 6 minutes at 20,30,40, 50 and $60 \%$ of the theoretical maximum power. Anthropometric and metabolic profiles of the subjects were thus assessed as before and after physical retraining program.

\section{Anthropometric and metabolic profiles}

\section{Anthropometric profile}

The amounts of fat mass, lean mass and total body weight of each subject were determined by dualenergy X-ray absorptiometry method (DEXA) (version 6.1 0.0 19; General Electric Lunar Corporation, Madison, WI) (Pietrobelle et al., 1996). The participant should remain lying on an examination table while an X-ray to low density swept his body for 10 minutes. The exposure amounts to 0.03 millirems for DEXA, which is less than the natural ambient exposure per day which is less than the maximum allowed dosage 5 millirems per year. The correlation coefficient for the fat mass and the lean body mass was $0.98(n=53)$. The standing height was measured using a stadiometer (Perspective Enterprises, Portage, MI).

The abdominal and hip perimeters were measured using a flexible and inelastic measuring tape with an accuracy of $0.5 \mathrm{~cm}$. The abdominal circumference was measured above the iliac crests on each side of the participant body. However, the hip circumference was measured at the level of the symphysis pubis and the maximum circumference of the buttocks (Kim et al., 2006). The measurements were taken three times and the average was retained unless value differs extremely from the other two. In this case, the value that was different was excluded and the average was made from the other two. The body mass index (BMI) was calculated as body weight $(\mathrm{kg}) / \mathrm{height}\left(\mathrm{m}^{2}\right)$ (Bertin et al., 2000).

\section{Metabolic profile}

The blood tests were performed on an empty stomach between 7.00 and $7 \mathrm{~h} 30$ min by a nurse using a venous catheter implanted in the antecubital vein. The samples were immediately aliquoted and stored at $-80^{\circ} \mathrm{C}$ until analysis. The biology of routine was assayed at the Service of Biochemistry of the University Hospital Center of Habib Bourguiba, Sfax. The total cholesterol, triglycerides, glucose were determined by dry-chemistry assay (Ektachem 700, Kodak) (Yamada et al., 2002), the HDL-cholesterol (HDLc) was also determined by the same method, after precipitation of the LDL with dextran sulfate $50000 \mathrm{D}, 0.9 \mathrm{~g} / \mathrm{l}$, in the presence of magnesium chloride, $45 \mathrm{mmol} / \mathrm{l}$. The LDL-cholesterol (LDLc) was evaluated by the Friedewald formula for samples with triglyceride concentrations were below $4 \mathrm{mmol} / \mathrm{l}$ (Friedewald et al., 1972). The levels of proinflammatory markers, interleukin-6 (IL-6) and Tumor Necrosis Factor-alpha (TNF- $\alpha$ ) were determined by the ELISA technique (Hawkes, 1999).

\section{Data analysis}

The analysis of variance (ANOVA) of results was made following a randomly complete block design (Snedecor and Cochran, 1957) by the GLM procedure of the SAS statistical package (SAS Institute, 1989). Homogeneity of variance was verified by the standard Bartlett test (Anderson and McLean, 1974).

\section{Results}

The formatting programs of the Tunisian obese pubescent boys began by determining the levels of this LipoxMax and advocate for each of them a retraining program in specific endurance. The average values thereof were in the range of $125.8 \pm 12.6 \mathrm{mg} / \mathrm{min}$.

Table 1 shows the anthropometric profile of the subjects before and following the retraining program in endurance on an ergometer cycle for two months at the rate of three sessions of 45 min per week. Levels of body mass, BMI, abdominal and hip perimeters, and fat mass of the subjects decreased after two months of the retraining in endurance. However, the lean body mass increases. However, these variations are not statistically significant $(\operatorname{Pr} \leq 0.05)$.

The levels of glucose, triglycerides, total cholesterol, LDLc of the patients decreased following the retraining program in endurance on an ergometer cycle for two months at the rate of three sessions of $45 \mathrm{~min}$ per week against that of the HDL that increases. However, these variations are not statistically significant $(\operatorname{Pr} \leq$ $0.05)$.

Table 1. Mean values \pm standard deviations of anthropometric profile of the Tunisian obese pubescent boys measured before and following 
the retraining program in endurance on an ergometer cycle for two months at three sessions of $45 \mathrm{~min} /$ week.

\begin{tabular}{|c|c|c|}
\hline \multirow[b]{2}{*}{ Profiles } & \multicolumn{2}{|c|}{ Retraining in endurance } \\
\hline & Before & After \\
\hline Body mass (kg) & $97.4 \pm 11.2$ & $92.3 \pm 10.9$ \\
\hline Height (m) & $1.7 \pm 0.1$ & $1.7 \pm 0.1$ \\
\hline BMI $\left(\mathrm{kg} / \mathbf{m}^{2}\right)$ & $33.6 \pm 4.1$ & $31.9 \pm 3.2$ \\
\hline Abdominal perimeter $(\mathrm{cm})$ & $102.2 \pm 11.0$ & $98.2 \pm 11.2$ \\
\hline Hip perimeter $(\mathbf{c m})$ & $117.9 \pm 11.5$ & $114.1 \pm 9.0$ \\
\hline Fat mass $(\mathbf{k g})$ & $35.3 \pm 8.0$ & $31.3 \pm 8.8$ \\
\hline Lean mass (kg) & $61.6 \pm 10.4$ & $62.0 \pm 9.1$ \\
\hline
\end{tabular}

Table 2. Mean values \pm standard deviations of metabolic profile of the Tunisian obese pubescent boys measured before and following the retraining program in endurance on an ergometer cycle for two months at three sessions of $45 \mathrm{~min} /$ week.

\begin{tabular}{|c|c|c|}
\hline \multirow[b]{2}{*}{ Profiles } & \multicolumn{2}{|c|}{ Retraining in endurance } \\
\hline & Before & After \\
\hline$\overline{\text { Glucose }(\mathrm{mmol} / \mathrm{L})}$ & $4.96 \pm 0.3$ & $4.58 \pm 0.4$ \\
\hline Total Cholesterol (mmol/L) & $3.9 \pm 0.7$ & $3.1 \pm 0.7$ \\
\hline HDLc (mmol/L) & $0.9 \pm 0.1$ & $1.2 \pm 0.1$ \\
\hline LDLc (mmol/L) & $2.7 \pm 0.7$ & $2.1 \pm 0.7$ \\
\hline LDLc/HDLc & $2.8 \pm 0.7$ & $2.0 \pm 0.7$ \\
\hline Triglycerides (mmol/L) & $1.4 \pm 0.4$ & $0.9 \pm 0.3$ \\
\hline
\end{tabular}

The levels of IL- 6 and TNF- $\alpha$ of the subjects decrease following the retraining program in endurance on an ergometer cycle for two months at the rate of three sessions of $45 \mathrm{~min}$ per week (Table 3). However, these changes were not statistically significant $(\operatorname{Pr} \leq 0.05)$.

Table 3. Mean values \pm standard deviations of pro-inflammatory profile of the Tunisian obese pubescent boys measured before and following the retraining program in endurance on an ergometer cycle for two months at three sessions of $45 \mathrm{~min} / \mathrm{week}$.

\begin{tabular}{|c|c|c|}
\hline \multirow[b]{2}{*}{ Profiles } & \multicolumn{2}{|c|}{ Retraining in endurance } \\
\hline & Before & After \\
\hline Interleukine-6 & $9.71 \pm 3.28$ & $8.9 \pm 2.2$ \\
\hline Tumor Necrosis Factor alpha & $11.40 \pm 3.25$ & $10.3 \pm 2.2$ \\
\hline
\end{tabular}

\section{Discussion}

Childhood obesity is defined as abnormal or excessive fat accumulation. It has become nowadays a global problem most often connected to social-economic development of the countries concerned and is a true marker of the cardiovascular prevalence risk and other diseases (Speiser et al., 2005). This metabolic abnormality involves genetic factors whose expression is often favoured by a sedentary lifestyle and changing dietary habits in obese (Dietz et al., 1994; Wiecha et al., 2006). Regular physical activity associated with caloric restriction can often increase daily energy expenditure and reduce overweight subjects (Eliakim et al., 1996; Lemmens et al., 2008).

We have recommended in our study a specific rehabilitation program for each Tunisian obese pubescent boys participating as a result of the determination of the LipoxMax levels and this to further enhance the beneficial effects of the retraining program in endurance. Our study showed that retraining in endurance positively affects the anthropometric and metabolic profiles of the Tunisian obese pubescent boys. Indeed, a reduction in body weight and therefore the BMI of patients resulting from the decrease in fat mass was observed at the end of physical retraining program period on ergometer cycle. These changes were also accompanied by the abdominal and hip' perimeters decrease and the preservation of the patients' lean body mass. Such observations have been reported by Goran et al. (1999) and Ben Ounis et al. (2008) on obese children following the training effort. Thus, Pouchain et al. (2007) reported that the increase in the size of abdominal perimeters in 
children results from the accumulation of fat, which may cause metabolic complications such as insulin resistance, diabetes, dyslipidemia and atherosclerosis (NHLBI, 1998).

Our study showed that the retraining in endurance reduces the levels of glucose, total cholesterol, LDLc and triglycerides, while it increases that of HDLc. This induced the reduction of the LDLc/HDLc ratio. Such results are consistent with those reported by Meyer et al. (2006), Natarajan et al. (2003) and Schmitz et al. (2002) who also indicated that the control of these metabolites by physical exercise significantly reduces the problems of atherosclerosis and diabetes in obese. Indeed, aerobic exercise which operates at a level of maximum LipoxMax promotes the lipid oxidation and its derivatives as well as of the glycogen (Brandou et al., 2003; Steinberger and Daniels, 2003; Zunquin et al., 2006).

Our study showed that the concentrations of IL- 6 and TNF- $\alpha$, two pro-inflammatory cytokines produced mainly in adipose tissue, decreased in obese subjects following the retraining program in endurance. Such results have been reported by Clements et al. (2004). These two substances have always been associated with cardiovascular disease, stimulation of the hepatic secretion of triglycerides, reducing of the effects of insulin etc. in the obese (Arnaud, 2006).

In conclusion, this study shows that the retraining in endurance on an ergometer cycle reduces the weight load of the Tunisian obese pubescent boys and improves their metabolic profiles.

\section{References}

[1]. Anderson VL., McLean RL. 1974. Design of experiments. Marcel Dekker, New York.

[2]. Arnaud B. 2006. L'obésité: Origine et conséquence d'une épidémie. C. R. Biol., 329: 562-569.

[3]. Ben Ounis O., Elloumi M., Amri M., Zbidi A., Tabka Z., Lac G. 2008. Impact of diet, exercise, and diet combined with exercise programs on plasma lipoproteins and adiponectin levels in obsess girls. J. Sports Sci. Med., 7: 437-445.

[4]. Bertin E., Marcus C., Ruiz JC., Eschard JP., Leutenegger M. 2000. Measurement of visceral adipose tissue by DXA combined with anthropometry in obese humans. Int. J. Obes. Relat. Metab. Disord., 24: 263-270.

[5]. Brandou F., Dumortier M., Garandeau P., Mercier J., Brun JF. 2003. Effects of a two-month rehabilitation program on substrate utilization during exercise in obese adolescents. Diabetes Metab., 29: 20-27.

[6]. Brown KW., Ryan RM., Creswell JD. 2007. Mindfulness: Theoretical foundations and evidence for its salutary effects. Psychol. Inq., 18: 211-237.

[7]. Clements K., Viguerie N., Poitou C., Carette C., Pelloux V., Curat CA. 2004. Weight loss regulates inflammation-related genes in white adipose tissue of obese subjects. FASEB J., 18: 1657-1669.

[8]. Cornier, MA., Dabelea D., Hernandez TL, Lindstrom RC, Steig AJ, Stob NR. 2008. The metabolic syndrome. Endocr. Rev., 297: 777-822.

[9]. Dietz WH., Bandini LG., Morelli JA., Peers KF., Ching PI. 1994. Effect of sedentary activities on resting metabolic rate. Amer. J. Clin. Nutr., 59: 556-559.

[10]. Dumortier M., Brandou F., Perez-Martin A., Fedou C., Mercier J., Brun JF. 2003. Low intensity endurance exercise targeted for lipid oxidation improves body composition and insulin sensitivity in patients with the metabolic syndrome. Diabetes Metab., 29: 509-518.

[11]. Eliakim A., Barstaw TJ., Brasel JA., Ajie H., Lee WN., Renslo R., Berman N., Cooper DM. 1996. Effects of exercise training on energy expenditure, muscle volume and maximal oxygen uptake in female adolescent. J. Pediatr., 129: 537-543.

[12]. Foschini D., Prestes J., Charro MA. 2007. Relação entre exercício físico, dano muscular e dor muscular de início tardio. Rev. Bras Cineantropom Desempenho Hum., 9: 101-106.

[13]. Friedewald WT., Levy RI., Fredrickson DS. 1972. Estimation of the concentration of low density lipoprotein cholesterol in plasma without use of the preparative ultracentrifuge. Clin. Chem., 18: 499-502.

[14]. Giannopoulou I., Ploutz-Snyder LL., Carhart R., Weinstock RS., Fernhall B., Goulopoulou S., Kanaley JA. 2005. Exercise is required for visceral fat loss in postmenopausal women with type 2 diabetes. J. Clin. Endocrinol. Metab., 90: 1511-151

[15]. Goran MI., Reynolds KD., Lindquist CH. 1999. Role of physical activity in the prevention of obesity via a school-based interdisciplinary intervention among youth. Arch. Pediatr. Adolesc. Med., 153: 409-418.

[16]. Griera JL., Manzanares JM., Barbany M., Contreras J., Amigo P., Salas-Salvado J. 2007. Physical activity, energy balance and obesity. Public Health Nutr., 10: 1194-1199 .

[17]. Hawkes JS., Bryan DL., James MJ., Gibson RA. 1999. Cytokines (IL-1 $\beta$, IL-6, TNF- $\alpha$, TGF- $\beta 1$, and TGF- $\beta 2$ ) and prostaglandin $\mathrm{E}_{2}$ in human milk during the first three months postpartum. Pediatr. Res., 46: 194-199.

[18]. Kim J., Peterson KE., Scanlon KS., Fitzmaurice GM., Must A., Oken E., Rifas-Shiman SL., Rich-Edwards JW., Gillman MW. 2006 Trends in overweight from 1980 to 2001 among preschool children enrolled in a health maintenance organization. Obesity, 14: 1107-1112.

[19]. Lemmens V., Oenema A., Kleep K., Henriksen H., Brig J. 2008. Asystematic review of the evidence regarding efficacy obesity prevention intervention among adults. Obes. Rev., 9: 446-455.

[20]. Meyer AA., Kundt G., Lenschow U., Schuff-Werner P., Kiensat W. 2006. Improvement of early vascular changes and vascular risk factors in obese children after a six month exercise program. J. Amer. Coll. Cardiol., 48: 1865-1870.

[21]. Must A., Spadano J., Coakley EH., Field AE., Colditz G., Dietz WH. 1999. The disease burden associated with overweight and obesity. JAMA, 282: 1523-1529.

[22]. Natarajan S., Glick H., Criqui H., Horowitz D., Lipsitz SR., Kinosian B. 2003. Cholesterol measures to identify and treat individuals at risk of coronary heart disease. Amer. J. Prev. Med., 25: 50-57.

[23]. NHLBI (National Heart, Lung and blood Institute). 1998. Clinical guidelines on the identification, evaluation and treatment on overweight and obesity in adults. Obes. Res., 6:51-209.

[24]. Pietrobelli A., Formica C., Wang Z., Heymsfield SB. 1996. Dual-energy X-ray absorptiometry body composition model: review of physical concepts. Amer. Physiol. Soc., 1: 941-951

[25]. Pouchain D., Amouyel P., Bringer J., Bruckert E., Charbonnel H., Dallongeville J. 2007. Obésité abdominale et facteurs de risque cardiovasculaire chez les adultes en médecine générale. Rev. Prat. MG., 21: 784-785. 
[26]. Ross R., Dagnone D., Jones PJ., Smith H., Paddags A., Hudson R., Janssen I., 2000. Reduction in obesity andrelated comorbid conditions after diet-induced weight loss or exercise-induced weight loss in men. A randomized, controlled trial. Ann. Intern. Med., 133: 92-103.

[27]. Rossner S., Hallberg D. 1978. Serum liporopteins in massive obesity. A study and after jejunoileal shunt operation. Acta Med. Scand., 204: 103-110.

[28]. SAS Institute. 1989. SAS/STAT User's Guide, ver. 6, vol. 2, 4th ed. SAS Institute, Cary, N.C.

[29]. Schmitz KH., Jacobs DRjr., Hong CP., Steinberger G., Moran A., Sinaiko AR. 2002. Association of physical activity with insulin sensivity in children. Int. J. Obes. Relat. Metab. Disord., 26: 1310-1316.

[30]. Snedecor GW., Cochran WG. 1957. Statistical methods. 6th ed. Iowa State Univ Press.

[31]. Speiser PW., Rudolf MC., Anhalt H., Camacho-Hubner C., Chiarelli F., Eliakim A. 2005. Childhood obesity. J. Clin. Endocrinol. Metab., 90:1871-1887.

[32]. Steinberger J., Daniels SR. 2003. Obesity, insulin resistance, diabetes and cardiovascular risks in children. Circulation, 107: 14481453 .

[33]. Wiecha JL., Peterson KE., Ludwig DS., Kim J., Sobol A., Gortmaker SL. 2006. When children eat what they watch: impact of television viewing on dietary intake in youth. Arsh. Pediatr. Adolesc. Med., 160: 436-42.

[34]. Yamada T., Nishino S., Takubo T., Hino M., Kitagawa S., Tatsumi N. 2002. Simple high-density lipoprotein cholesterol assay based on dry chemistry. Clin. Chim. Acta, 320: 79-88.

[35]. Zunquin G., Theunynck D., Sesboué B., Arhan P., Bougle D. 2006. Effets de la puberte' sur la balance glucidolipidique lors de l'exercice de l'enfant obèse. Appl. Physiol. Nutr. Metab., 31: 442-448. 